\title{
Negotiating Race and Ethnicity: exploring the implications of the 1991 Census $^{1}$
}

Roger Ballard

While the decision to include an explicit ethnic question in the 1991 Census of the United Kingdom was undoubtedly a major step forward, it is nevertheless still one whose precise meaning and significance is still clouded by a great deal of uncertainty. There are many reasons why this should be so. First of all, the concept of ethnicity itself is a relative newcomer to the vocabulary of social science, and no comprehensive consensus about its meaning has yet emerged. Understandings vary: while most specialists in the field insist that ethnicity is a phenomenon which must be understood in its own right, the term is nevertheless still often deployed as little more than a sanitised euphemism for the otherwise morally discredited concept of race. ${ }^{2}$ A second set of confusions arises from the first, for there is consequently no consensus about what the purpose of asking such a question might be, nor about the kinds of issues which the answers might serve to illuminate. Even so, remarkably little attention has been paid to the underlying issues. To be sure the proposal to include an ethnic question in the Census precipitated a lengthy and often heated public debate, as Bulmer shows in the previous Chapter, but little or none of this was directed at establishing the meaning of the question itself.

Given the importance of the initiative, and the fact that both race and ethnicity refer to far less easily objectifiable personal attributes than such routine census categories as age, sex, marital status and place of birth, one might have expected that at least some attention would have been focused on what ethnicity actually meant, rather being directed almost exclusively on whether or not the question should be asked. With hindsight, the absence of such a debate was most unfortunate. Not only were the underlying conceptual issues left unclarified, but the question actually posed - and as we shall see in a moment finding a viable form of words proved to be far from easy - was much more a pragmatic compromise than the product of a clearly worked out analytical perspective. To be sure the new question "worked": there were few objections to its inclusion in the Census, and it also achieved a good response rate. This pragmatic success was far from cost-free, however, for its success depended on overlooking a whole series of internal contradictions, which in turn left considerable scope for the question to be interpreted in different ways. If respondents of differing backgrounds responded to these ambiguities by reading differing meanings into the question - and as we shall see there is a good deal of evidence that this did indeed occur - it follows that the raw results should be approached with considerable care.

Hence even though the inclusion of an ethnic question has undoubtedly added an important new dimension to the Census, deciding how data associated with the new Ethnic Group variable can best be interpreted is by no means a straightforward task. Since it would therefore be most unwise to rely on nothing more than commonsense understandings in this context, my central objective in this chapter is to bring the underlying issues into clearer analytical focus.

\footnotetext{
This paper was originally prepared for inclusion in David Coleman and John Salt (eds.) Ethnicity in the 1991 Census: demographic characteristics of the ethnic minority populations, the first of the four volumes of commentary on the results of new question published by O.P.C.S. However it was eventually rejected by the editors on the grounds that my approach approach was "too speculative". In the interests of scholarship I have left the text unchanged, despite its appearance in a context very different from that for which it was originally written.
}

2 A comprehensive overview of recent discussions about the nature of ethnicity can be found in Eriksen 1993. 


\section{Roger Ballard}

To this end I begin with a brief review of the current state of racial inequality and ethnic diversity in Britain, both to set the issues in a wider context and to highlight the differing significance of the concepts of race and ethnicity. Having done so I then move on to consider the way in which the question itself was constructed, which in turn helps us to bring into clearer focus both the kind of information which we can expect it to have elicited, and hence the kinds of issues which we can expect the answers to illuminate. Doing so not only highlights the ways in which ethnic data can best be understood and utilised, but also poses some far-reaching challenges to many established assumptions about the most appropriate way to conceptualise social inequality and cultural diversity, regardless of the vector along which it occurs.

\section{Ethnic Diversity in Contemporary Britain}

If we were to follow the vernacular usage which regards ethnicity as little more than a synonym for race, it would be easy to conclude that ethnic diversity in Britain is a late twentieth century phenomenon which was precipitated by the arrival of non-European labour migrants in the aftermath of the second world war. To be sure the arrival of substantial numbers of Commonwealth citizens from Asia, Africa and the Caribbean during the course of three decades of nearly-continuous industrial growth between 1950 and 1979 had a radical impact on the character of the British social order. Not only did it became much more overtly multi-racial and poly-ethnic than it had been before, but the social tensions precipitated by these changes were primarily responsible for the eventual inclusion of an ethnic question in the Census. Even so it would be a grave mistake to assume that either large scale immigration or the ethnic diversity which it precipitated was in any way a novel phenomenon.

During the latter part of the nineteenth century Irish Catholic migrants settled in the major industrial cities of England and Scotland on an even larger scale, to be followed by a rather smaller - although no less socially significant - inflow of Eastern European Jews at around the turn of the century. During the economic recession which followed the first world war immigration almost ceased, but in the immediate aftermath of the second world war it soon picked up again, when several hundred thousand "European Voluntary Workers" - mostly from Poland, the Baltic States and the Ukraine - were recruited to fill the vacant slots in Britain's rapidly expanding labour market. However by the early nineteen fifties these sources had ceased to be in a position to satisfy Britain's demands for additional labour power, so migrant workers began to be drawn in from further afield, and most especially from Britain's former Imperial possessions in Asia, Africa and the Caribbean.

Even though the 1991 ethnic question was only concerned to identify this latter group of migrants and their British-born descendants, it would be idle to overlook the parallels between the causes and consequences of their arrival and that of their (albeit less immediately visible) predecessors from Ireland and Eastern Europe. Each one of these inflows was precipitated by similar patterns of labour shortage, while the growth of each successive minority community precipitated much the same kind of alarm and hostility amongst the settlers' indigenous neighbours (Holmes 1991). Moreover hostility towards the newcomers was invariably articulated along two complementary dimensions. Firstly each group of settlers soon began to be regarded as unwelcome competitors for scarce material resources, especially when the boom which had precipitated the migratory inflow was subsequently followed by economic recession; such tensions also tended to become all the more acute once settlers, and especially their locally born offspring, began to compete for access to scarce resources beyond the least attractive areas of the employment and housing markets which they initially occupied.

However straightforward material competition, vigorous though it often became, was but only the first dimension of majority hostility; the second focused on the perceived threat of 
minorities' commitment to maintaining a sense of religious and cultural distinctiveness, which soon came to be regarded as offering as much if not more of threat to indigenous interests than that arising from their role as competitors for the same limited set of material resources. These fears tended to be further reinforced once it became obvious that the minorities' distinctive religious and cultural commitments were not a temporary phenomenon which would soon be eclipsed by assimilation, but rather a permanent feature of their presence. Hence, for example, the belief that Irish immigrants were not only stealing jobs from honest English workers, but were also part of a deep-laid Papist plot to undermine Englishness, Protestantism and the Crown was both widespread and exteremely popular during the late nineteenth century (Fielding 1992).

Yet despite the many parallels, there was one crucial difference between the two sets of immigrants - physical visibility. Even though popular belief in the late nineteenth century held that Irish and Jewish people were racially different from the native English (for this was an era during which biological interpretations of the roots of social difference ruled unchallenged), both Irish and Jewish settlers - and most especially their offspring — had a realistic option of adopting forms of behaviour which would render them virtually indistinguishable from the native English. By contrast their post-war successors of non-European descent had no such option, for their skin colour was an inescapable social marker, and remains so to this day: for them "passing" was not, and still is not a realistic possibility. Nor is that all. Besides being members of a visible minority who are thereby easy targets for racial exclusion, they also stand right at the back of the queue of labour migrants, since recent advances in manufacturing technology make it most unlikely that Britain will ever again need to recruit migrant workers in large numbers to sustain its productive base. Hence the new minorities are in a much more vulnerable position than any of their predecessors. Quite apart from their easy identifiability, they cannot look forward to the arrival of successor-scapegoats as a diversionary focus for majority hostility.

In the face of all this, members of the new minorities have had particularly good reason to close ranks, and turn to the resources of their own distinctive religious, cultural and moral traditions as a means of organising mutual support, the better to survive the exclusionism they so routinely encountered. The result of all this is now plain to see: flourishing ethnic colonies, within which large parts of the social linguistic religious and cultural traditions have been reproduced, are now a very salient feature of Britain's urban landscape. Yet although these developments have now become a routine target of majority hostility, since it is noticeable that popular complaints tend to focus much more on the minorities' cultural than on their physical distinctiveness, such tensions are neither so unique nor so unprecedented as is invariably supposed. Quite the contrary. Each successive group of labour migrants regardless of their physical appearance - behaved in much the same way. Each group treated the resources of their imported traditions as cultural capital, and on this basis built up networks of mutual reciprocity, both as an immediate survival strategy to meet the challenge of their new environment, and even more so as a means of resisting the xenophobic hostility they so often encountered. Hence the arrival of every single migrant group - whether of Irish, Jewish, Polish, Latvian, Ukrainian, Yemeni, Jamaican, Barbadian, Punjabi, Gujarati or Sylheti extraction - precipitated the construction of a new set of ethnic colonies. ${ }^{3}$

With hindsight it is not difficult to view such developments as inevitable, even though the growth of such colonies was rarely regarded with equanimity at the time of their emergence. Although from the settlers' perspective ethnic consolidation was no more than a sensible, and indeed a very constructive adaptive strategy, their indigenous neighbours invariably took the

3 Mayhew (1861) provides some graphic accounts of Irish and Jewish ethnic colonies in late nineteenth century London. Accounts of parallel developments in more recent times can be found in Watson (1977) and Ballard (1994). 


\section{Roger Ballard}

opposite view, such that the newcomers' preferred survival strategies soon became a focus for ire and resentment. It is as an outcome of such processes that the popular nineteenth century view that Irish immigration was part of a deliberate Papist threat to England's cultural and religious integrity is best understood, as is the way in which successive Aliens Acts which were passed in the early years of this century, and whose aim was to halt further Jewish settlement gained equally widespread popular support on the grounds that the sewers of Europe would at long last be prevented from emptying themselves into Britain's cities. Current paranoias about the threat which "fundamentalist Muslims" and "criminally inspired Rastafarians" allegedly offer to the integrity of the British social order therefore have some very clear historical precedents.

Yet however regular the development of such xenophobic hostility towards immigrant minorities may have been, both the intensity of these sentiments and the length of time for which they have been sustained has varied a great deal. Hence when Jewish settlers began to arrive in significant numbers towards the end of the nineteenth century, hostility towards their Irish predecessors declined; and when non-European migrants began to arrive in large numbers in the nineteen fifties, it was they who became the quintessential "immigrants", and have remained so ever since. Much has also depended on the precise way in which the members of each successive group sought to manage their relationships across the ethnic boundary. One very effective way of reducing the impact of majority exclusionism - if not the underlying level of hostility — was for individuals to eliminate any overt sign of distinctiveness (at least in all public domains), such that they could "pass" as being identical with everyone else. Such possibilities serve to underline the strongly contextual nature of ethnic expression, and also that public appearances may well be wholly at odds with private realities. Hence even though many Irish and Jewish settlers - and most especially their locally-born offspring — went to considerable lengths to "pass" in this way, their behaviour in more personal and domestic domains is often far more distinctive than their carefully crafted public appearances might suggest. The advantages of such behaviour are obvious enough: those who pursue such strategies can hope to make the best of both worlds, simultaneously maximising the benefits of ethnic solidarity whilst also minimising the likely impact of xenophobic hostility. Many sections of Britain's Jewish population have long pursued just such a strategy, which are now deployed with great skill, success and sophistication. ${ }^{4}$

Since strategies of ethnic consolidation offered so many benefits to their less visible predecessors, it is hardly surprising that more recent settlers of non-European origin are doing just the same. However in their case the option of "passing" — of giving a public appearance of assimilation while privately maintaining a great deal of distinctiveness in more domestic spheres — is both less attractive and far less effective. Quite apart from the psychological humiliation which a denial of one's ancestral roots necessarily entails, such measures simply do not bring the acceptance that is so desperately sought. Since skin colour remains an inescapable social marker in the eyes of the indigenous majority — as members of the new minorities are only too aware - their physical appearance alone is sufficient to precipitate exclusion and devaluation, no matter how "English" their behaviour and self-presentation may be. It is for this reason that while a few members of the newer and more visible minorities are still doggedly pursuing a strategy of comprehensive assimilation, most are more or less strongly committed to maintaining a public indication of their ethnic distinctiveness, rather than confining it wholly to the private domain. They have little to lose by doing so, and such a strategy also offers some positive advantages: above all the opportunity to resist racial and

\footnotetext{
4 Detailed accounts of such strategies, which were pursued with particular vigour in the nineteen thirties as the second generation sought to battle their way into professional occupations in the face of intense exclusionism, can be found in Alderman (1993) and Brook (1991).
} 
ethnic denigration in an overt way, instead of hoping that it will pass them by and go away of its own accord.

This is clearly no place for a full discussion of the extent to which Britain has become a racially and ethnically plural society, but having identified the basic dynamics of the underlying processes, some broad points can be stated in summary fashion:

a) While the majority of post-war immigrants differed from their predecessors because they were physically distinguishable, each successive group of labour migrants faced a considerable degree of xenophobic hostility, to which they responded by (amongst other things) closing ranks in ethnic solidarity.

b) Since their origins varied widely, the cultural capital deployed by each group in the process of ethnic colonisation has been exceedingly varied; hence their trajectories of adaptation - and of social mobility — have been far from uniform.

c) Although every group has pursued a broadly similar strategy of ethnic consolidation forming kin-based residential clusters within which they have established their own schools, places of worship and centres for leisure and relaxation - the degree of public salience accorded to these activities has varied greatly. The newer minorities have made little effort to obscure their alternative existences, while most members of the longer-established nonvisible minorities have quite deliberately sought to underemphasise both the existence and the extent of their distinctiveness, most especially in public arenas. ${ }^{5}$

\section{Ethnicity and the 1991 Census}

Set against this background, the ethnic question which was actually posed in 1991 was a curiously limited exercise. Far from seeking to explore the scale of ethnic diversity in Britain in the sense outlined above, it was almost exclusively concerned with identifying members of Britain's visible minorities. In pragmatic terms it is not difficult to see how this came about. First, if the introduction of the question reflected majority concern about the extent of ethnic diversity, then it was the presence of the visible minorities about which they were virtually exclusively alarmed. Second, many of the invisible minorities had grave reservations about the wisdom of raising their heads above the parapet. Jewish memories of the Holocaust were still vivid, and hence they were very conscious that permitting the state to identify them public had recently been the first step towards genocide; meanwhile England's reactions to Ulster's troubles had made led Britain's very substantial Irish Catholic community to be equally doubtful about the wisdom of flagging their distinctiveness. Third, while members of the visible minorities had some particularly good reasons to doubt the bona fides of the state, they were nevertheless becoming increasingly conscious of — and steadily more assertive about their distinctive interests and concerns. Thus while their reasons for doing so could hardly have been more varied, almost everyone, whether they belonged to the indigenous majority or to the invisible or the visible minorities, took it for granted that the new ethnic question would

\footnotetext{
5 Although there is no space to discuss them in detail, Britain's Jewish population provides some very illuminating insights on these procedures. When immigration of Eastern Europe was at its height in the closing decades of the nineteenth century, the long-established Jewish elite (most of whom were Sephardi) made strenuous efforts to persuade the Ashkenasi newcomers to abandon their traditional ways and to assimilate as soon as possible — with very little success. By the nineteen thirties, when many of the British educated second generation were forcing their way into the professions in the face of fearsome opposition, the passing strategy outlined here reached its peak. Today, however, a significant number of Jewish students make a public indication of their ethnicity by wearing the yarmulke, while the inhabitants of the Ultra-orthodox ethnic colonies in areas such as Stamford Hill and Broughton Park make no effort to hide their distinctiveness. But as the dispute over the North London eruv demonstrated, British Jewry is bitterly divided over the issue of whether or not they should make any kind of public indication of their distinctiveness.
} 


\section{Roger Ballard}

be targeted solely on the latter group. Ethnicity was therefore assumed to be synonymous with physical visibility.

This assumption had many important consequences. Not only did it further obscure the distinctive character of the less visible minorities, but it also entrenched an even more serious deficiency: the possibility that Britain's indigenous majority might also be in some way ethnic. Is it the case that ethnicity is solely an adjunct of minority and/or immigrant status, as popular parlance still routinely suggests? Or must we take a different perspective? My own view is that until we disentangle ourselves from the limitations of the conventional equation, however commonsense it may seem, serious discussion of Britain's current condition of ethnic diversity will remain virtually impossible.

\section{Majority perspectives on their own ethnicity}

One of the central privileges — albeit doubtful — of belonging to a hegemonic majority is that one can take the normality of one's own social and cultural conventions wholly for granted. Hence in plural societies where the majority enjoys a position of unchallenged hegemony, it is easy for members of that group to regard their own behaviour as so completely unexceptional, such that only the lifestyles of others appear to be sufficiently extraordinary and deviant to justify the use of the adjective "ethnic". While the tendency to understand difference in this way is by no means unique to Britain, the view that ethnicity is solely a characteristic of exotic others is seriously mistaken. Analytical objectivity requires us to recognise that the majority differs from the minorities just as much as minorities differ from the majority.

If, then, we seek to explore both sides of the coin - as we must do if we are to avoid unjustifiably privileging the majority perspective - care must be taken to distance ourselves from the procrustean limitations of our conventional assumptions. This can be achieved by taking a short but highly significant step: instead of viewing minorities as different, such that they are perceived as somehow deviant from the unstressed yardstick of majoritarian normality, we should adopt a more analytically neutral premise: that whatever their size, history or power, all the various ethnic segments of Britain's population simply differ from each other. All are therefore equally British; and all are therefore equally ethnic and/or exotic. Although those sections of Britain's population who have long taken their hegemonic position for granted - such as the native English - may well find the adoption of such an analytical stance most unsettlling, the analytical advantages which accrue from doing so are considerable. Once envisioned as a plural society, Britain can more easily be perceived as a society in which a multiplicity of ethnic groups, both minority and majority, interact together within the framework of a single overarching social order. Besides facilitating an escape from the pitfalls of ethnocentrism, this perspective also serves to highlight the fact that Britain's wholly indigenous majority reveals is in fact far less ethnically homogeneous than the native English commonly suppose.

The tendency for internal diversity to be overlooked can be clearly illustrated by noting that most English people routinely use the term "British" as if its meaning was wholly synonymous with "English" — and in so doing systematically ignore the fact that the United Kingdom is both de facto and de jure a multi-national society. By contrast Britain's Scots and Welsh communities regard this this elision as offering the clearest possible evidence that the English are unwilling to acknowledge, let alone to respect, the ethnic distinctiveness of their Celtic fellow-countrymen. Yet in a further paradox, the English seem at present to have very great difficulty in identifying themselves in a positive way. In general they appear to find it far easier to identify themselves by contrast with alien others (and not least with reference to the latest group of "immigrants", whoever they happen to be) than to do so in more positive terms. 
Hence despite the threat that those other have regularly been held to offer to their integrity, just what such Englishness actually consists of remains obscure and largely unconsidered.

Yet despite the strength of English sensitivities, there is no reason in principle why discussion of ethnic pluralism in Britain should necessarily be constrained by such parochial concerns; and if it had not been, one might have expected that the 1991 Census might at least have attempted to make a systematic exploration of ethnic diversity. This would not only have entailed identifing all of Britain's many migrant minorities, whether visible or invisible, but also making an attempt to differentiate between the majority population's English, Scottish, Welsh and Irish components.

\section{The Ethnic Question in the 1991 Census}

Yet perhaps because an over acknowledgement of the intrinsically plural nature of British society would threaten so many entrenched interests and assumptions, neither the 1991 ethnic question itself, nor even the debate about whether or not it should be posed at all, even paid lip-service to such a possibility. Instead it was almost universally assumed that the object of the exercise was to identify members of Britain's visible minorities, the implications of whose presence had become a matter increasing public concern. That concern had several dimensions. To some, sheer numbers were an issue in its own right, especially as this section of the population was growing with considerable rapidity; to others, and especially to many Local Authorities, accurately establishing the size of the minority population in its area was an important objective since it could be used to support an argument for a larger Rate Support Grant from Whitehall; and to others yet again accurate statistics were a necessary prerequisite in any attempt to measure the extent of racial discrimination.

Yet despite the consequent interest in the scale and character of the visible minority population, and the increasingly acrimonious tone of public discussion about these developments, accurate statistical and demographic data was hard to come by given the absence of a properly formulated ethnic question in the Census. To be sure birthplace figures could be used to provide some very instructive clues, but there were two main flaws in using this data to estimate the scale of the minority presence. Firstly the birthplace data included an unknown number of people of wholly indigenous descent who had been born in one or other of Britain's overseas possessions; and secondly these figures excluded the locally-born children of immigrant parents, whose numbers were known to be growing very rapidly. In the 1981 Census this latter deficiency was partially remedied by the publication of tables of aggregate data for the residents of households whose heads were born either in either the New Commonwealth or Pakistan (rather than in Old Commonwealth countries such as Canada and Australia who could be expected to be white) which could then be used as a surrogate source of ethnic data. These figures were indeed a very useful guide to the scale and character of the most important segments of the visible minorities (Ballard 1983), but even so the technique was at best a stop-gap measure, since it failed to catch the steadily increasing number minority households with a British-born head. If accurate data was to be produced, it was clearly essential to pose a properly formulated ethnic question.

O.P.C.S. had in fact long been aware of the desirability of more accurate modes of data collection, and considerable efforts were made to ensure that an ethnic question would be included in the 1981 Census. However the very suggestion sparked off a very vigorous debate about the legitimacy of doing so at all,so much so that the proposal was eventually dropped completely. Nevertheless this was regarded as most unsatisfactory outcome in many quarters, so much so that the House of Commons Select Committee on Home Affairs held hearings on the subject during the course of 1982 and 1983. While their Report (H.C. 33-1, Vols. 1 and 2, 1983) came down very firmly in favour of asking ethnic questions, so virtually guaranteeing its 


\section{Roger Ballard}

inclusion in the 1991 Census, the arguments which were advanced for and against doing so are still well worth reviewing.

\section{Objections, objections}

Opponents of the question objected to its introduction on very diverse grounds. One major strand of argument - frequently, although by no means exclusively, articulated by the white left - held that to ask such a question was both morally and politically objectionable. Besides reifying the fictional concept of "race", those who took this position very often also argued that the state, the media, and indeed majority opinion were so hostile to the interests of the minorities that the results would inevitably be used to put them at a further disadvantage. This view was further reinforced by Jewish people's recent (and very emotional) memories of the holocaust, which left many of them with strong feelings that any attempt by the state to formally classify the population in racial terms must be vigorously opposed. Yet although all the most vigorous objections heard by the Select Committee articulated one aspect or another of these arguments, hostility to the introduction of an ethnic question was by no means confined to the left of the political spectrum. Although rarely explicitly articulated, such objections were supplemented by a widespread, if inchoate, popular feeling that such questions constituted an unwarranted intrusion into personal freedom. In this contexts some unexpected alliances appear to have been formed. For example despite Mrs. Thatcher's well-known fears about the scale of the minority presence, it has been widely suggested that it was on her instructions that the question was dropped from the 1981 Census. If so, this may well have reflected some careful political calculation. If reliable statistics on a given issue are unavailable, Government is better placed to resist pressure to take positive steps to address it, on the grounds that this would be unwise in the absence of adequate statistical data.

What, though, about minority responses to the prospect of the introduction of an ethnic question? While members of the visible minorities may indeed have had good grounds to distrust the bona fides of the British state - as radical opponents of the question never tired of arguing — field trials of possible questions conducted by O.P.C.S. between 1975 and 1989 provide little or no support for the view that a very high refusal rate from the minorities was inevitable. Far from it. In every exercise the response rate was generally good, provided that one crucial condition was met: that the itself question was posed in a non-alienating way. Hence if there were problems they lay much more in the form of the question than in the existence of the question itself.

Nor is it difficult to see why. First of all any formulation which allowed or encouraged the white majority to identify themselves as "British" with no further qualifications invariably caused problems, since it followed that anyone who ticked any of the other boxes would thereby implicitly identify themselves as in some sense "not-British". Yet even if that pitfall was avoided, a second problem - which ultimately proved to be even more serious - arose when the only option offered to British-born people of Afro-Caribbean descent to identify themselves was by associating themselves with their parents' geo-historical roots in the West Indies. While most British-born people of Asian descent were much less touchy on this issue, and therefore happy enough to identify themselves as Indian, Chinese, Pakistani and so forth, those of Afro-Caribbean descent often objected vigorously to the prospect of being expected to do so. As far as they were concerned, such an association with their parents' birthplace was perceived as compromising their Britishness.

Hence if the minorities objected to the content of ethnic questions, they usually did so for very good reason. Their central concern was with the way in which diversity was being conceptualised, and hence with the role in the wider social order to which they were implicitly allocated by the wording of the question. them. Unlike the white majority they had no 
objection to a public recognition that Britain had become a plural society: to them, at least, that was quite self-evident. What they did find deeply offensive - understandably enough was any indication that their distinctiveness might be read as an indication that they were in some sense not-British.

\section{A racial or an ethnic question?}

That the minorities should have been acutely aware of the issue of pluralism, and hence particularly insistent that they should not be identified in such a way that might indicate that they were not an integral part of the wider whole is hardly surprising. Nevertheless finding a form of words with which all sections of the population could feel at ease proved to be exceedingly tricky, not least with respect to the indigenous majority. Since minority objections effectively precluded the unqualified use of the term "British" to describe them, two main alternatives were available. Either they could confront the reality of ethnic pluralism head on, which would at the very least require all sections of the indigenous population to implicitly accept their hyphenated status as English-, Welsh and Scottish-British people, so leaving the way clear for categories such as Irish-British, Indian-British, African-British and ChineseBritish to be included in the same series; on the other hand the second alternative was to dodge the issue all together by entirely abandoning an ethnic vocabulary and replacing it instead with a vocabulary of race, or at least of colour. Hence the indigenous majority could be identified as White, leaving everyone else to be classified as in some sense non-White.

As far as Britain's indigenous majority are concerned, it would appear that either option offered the prospect of constructing a viable - or in other words an askable - question. In the 1979 Census trial, for example, native British respondents were invited to identify themselves as "English", "Welsh", "Scottish" or "Irish" the response rate was good, and certainly no worse than when they were presented with the identifier "White", as in almost all other trials as well the 1991 Census itself. Yet even either approach was equally viable, the difference between them was conceptually momentous. Had the first option been adopted the indigenous majority would have been invited to define themselves primarily in ethnic terms; however the second option, which was in fact the basis of the question finally posed in the census itself, offered a very different perspective, for the majority were in that case invited to identify themselves as members of a physically distinctive racial category.

This is not to suggest that O.P.C.S. was hell-bent on racialising the Census: indeed all the indications are that those involved in devising the question were wholly unaware that there were issues of any significance at stake here: on the contrary their preference for a racial as opposed to an ethnic perspective seems to have been largely pragmatic. With hindsight, however, their choice can be regarded as most unfortunate, since the introduction of the new question was such a propitious moment for the establishment of an ethnic rather than a racial perspective on British pluralism. To fall back on a vocabulary of colour was a huge missed opportunity for the indigenous majority to identify itself in a more positive way.

What, though, about labels which offered to the visible minorities as a means of identifying themselves? Once again O.P.C.S. appears to have proceeded in a largely pragmatic way, aiming only to find labels with which members of those minorities which it wished to identify could feel at ease. As all the various trial questions soon demonstrated, ethno/national labels such as "Indian", "Pakistani", "Bangladeshi", "Chinese", "Cypriot", "Arab" and "African" brought a positive response from members of those groups - always provided that the question was laid out in such a way that ticking boxes so labelled carried no suggestion that such groups were in any way un-British; and when South Asians were invited to further differentiate themselves as "Hindus", Muslims" and Sikhs", in the 1985 trial, they gave an equally positive response. There was, however, one group with whom the trials consistently 
ran into trouble: people of Afro-Caribbean descent, and most especially those who were British born. The problem encountered in the trials proved to have two linked dimensions. Firstly all members of this group, whether immigrant or British-born, proved to be far more sensitive than their Asian and African counterparts about the possibility that their association with ethno-national labels such as "West Indian" or "Afro-Caribbean" might seem to imply that they were in some way not-British. Secondly many of the British-born offspring of AfroCaribbean parents proved to have particularly strong objections to the use of any external geographical identifier. The Caribbean, they argued, had no meaning in their case: they had not been born there, nor was the Caribbean part of their British experience, whatever their white compatriots might assume. For them their Britishness (which should not, of course, be confused with Englishness) was a crucial part of their being. Hence in their case the identifier with which they felt least uneasy was the term "Black British".

Resolving the varying perspectives on self-identification amongst different segments of the minorities proved to be even more challenging than finding a suitable identifier for the indigenous majority. On the face of it, a very easy way out might have seemed to be available: a parallel retreat into a vocabulary of colour. If the majority were content to identify themselves as "White", why not offer the visible minorities the opportunity to identify themselves as "Black" — or at least "Black-British"? Such a resolution of the problem was indeed quite widely advocated, but amongst the minorities the only group amongst whom it found much favour was the Afro-Caribbeans; by contrast the great majority of British Asians argued either that they were not Black, or that if they were they were, they were Black in a very different sense from the Afro-Caribbeans. Could Black therefore be used identify everyone of African descent? Although that usage certainly made better sense, it by no means received universal support even amongst people who ancestral roots lay in Africa. Thus while the first generation of Afro-Caribbean settlers often vehemently insisted that they were not to be mistaken for Africans, West Africans tended to be equally insistent that they should not mistaken for the descendants of slaves. In other words groups had serious reservations about being subsumed under the same categorical label.

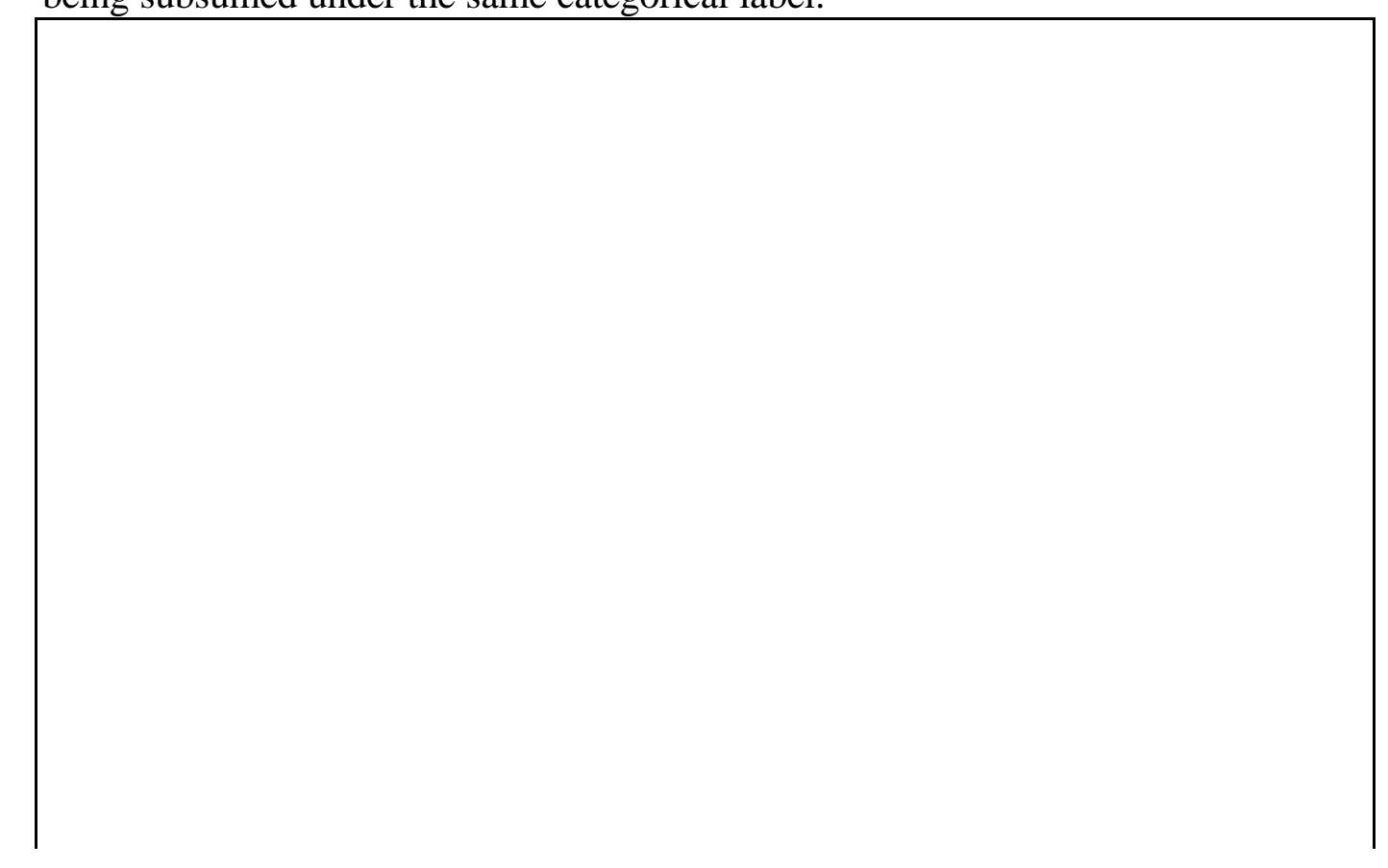

Faced with all these contradictions, the form in which the "Ethnic Group" question was a masterly piece of compromise which proved to be remarkably operationally effective. Despite many potential pitfalls, the response rate was high, and there were very few objections to its 
inclusion. Yet given the pragmatic nature of the exercise, it is hardly surprising that the chosen format was in not the outcome of a systematic attempt to address the underlying analytical issues at stake, but rather of a thoroughgoing effort to dodge them. That O.P.C.S. should have pursued this strategy on operational grounds is thoroughly understandable. They had a Census to run, and the question worked to the extent that it produced large amounts of data in a reasonably straightforward way. But the production of numbers is one thing, and knowing what they mean is quite another; as we shall see while the chosen compromise undoubtedly produced results, these were achieved at the cost of leaving many important questions unasked, and even the answers to the questions which were as need careful interpretation if we are to read them aright.

What, though, about the question itself? Perhaps the first point to note is that respondents were given no specific instructions as to the meaning of the term "Ethnic group": they are simply instructed to tick the appropriate box. Secondly the layout of the boxes seems implicitly to invite respondents to sort themselves into one or the other of three broad categories, White, Black and (even though the explicit colour identifier is omitted) Brown; beyond this the "White" category offers no further subdivisions, while the other two invite respondents to further identify themselves in ethno-national terms, as well permitting additional write-in answers.

How, though, did respondents deal with the question? As can be seen in Table 1, the overwhelming majority simply ticked the "White" box; of those who took the opportunity to identify themselves in some other way, most once again identified themselves unambiguously by ticking boxes $1-6$, with only $1.35 \%$ of the total population opting to take advantage of the "Black-Other" and "Any other ethnic group" write-in options. At one level the low level of write-ins can be regarded as a very satisfactory outcome, such answers are necessarily much more difficult to categorise than ticked boxes; even so O.P.C.S. went to considerable lengths to make the most of the write-ins, which were initially coded into 28 categories before finally being redistributed between the 10 output categories deployed in virtually all the published tables.

0 Responses to the Ethnic group question

Source: Ethnic Group and Country of Birth Volume: Table A

0 Initial classification of write-in responses

Source: Ethnic Group and Country of Birth Volume: Table A 


\section{Roger Ballard}

However figures in Table 2 reveal that despite the considerable efforts which were made to meaningfully classify the write-in responses, the results of the exercise turned out to be of very limited utility. Of those who filled in the "Black-Other" box, the largest group, no less than $26 \%$ of those in this category, appear simply to have identified themselves as "British", while almost as many responded in such a way that they were classified either under "other answers" or "other mixed". Analysis of the responses to the even more catch-all "Any other ethnic group" box proved to be slightly more illuminating in ethnic terms, since those classified either as "Other Asian" or "North African, Arab or Iranian", stand out from the mass; it would be a gross mistake to assume, however, that the figures in Table 2 offer a reliable guide to the size of Britain's smaller minorities. Estimates of the scale of such groups are best made from a study of the answers given to the birthplace question.

0 Ethnic group membership for persons born in selected non-European countries and regions.

Source: Ethnic Group and Country of Birth Volume, Table 5.In doing so, the data can be approached in two rather different ways: either through a straightforward tabulation of ethnic group by country of birth, as in Table 3, or of ethnic group by the country of birth of the head of the household in which that person is resident, as in Table 4. As the first set of figures reveals, relationships between birthplace and recorded ethnic group is both complex and extremely varied, and often require detailed exegesis. Sometimes the patterns are relatively easy to interpret, as in the case of those born in East and Central Africa, where 60\% identified themselves as "Indian", a further $20 \%$ as "White", and just $10 \%$ "Black African". This certainly fits with intuitive expectations where the first group would be East African Asians, the second white colonial settlers and their offspring, and the third native Africans. Similarly while $80 \%$ of those born in China identified themselves as "Chinese", it is noteworthy that Vietnamese-born people are equally split between "Chinese" and "Asian Other", reflecting a division between ethnic Vietnamese and ethnic Chinese. But while these interpretations help to illuminate the data, the results are far more confusing in the case of people from the circumMediterranean region. For example, while Table 2 shows that the coders were well-primed to pick up anyone who offered "Cypriot" as a write-in answer, Table 3 demonstrates that virtually all Cyprus-born people (who would, of course, have included a small number of those who were the locally offspring of British servicemen) must have ticked the "White" box on the census form. For much the same reason there is good reason to suppose that a large proportion of those born in North Africa and the Middle East and who responded in such a way that they were coded as "White" may also be of non-European descent. Given that answers to the ethnic question by itself may not, in such circumstances, be very illuminating, a tabulation of ethnicity by birthplace of household head can be most revealing.

0 Ethnic group by birthplace of head of household.

Source: Local Base Statistics, 100\% data for Great Britain. As ever we are limited by the formats in which O.P.C.S. has chosen to present the data, but nevertheless the patterns revealed in Table 4 are worthy of close consideration. If we continue to keep the Cypriots in focus for a moment, there is good reason to suppose that the 113,901 people who show up in the first column of Table 4 provides a much better indication of the size of Britain's ethnic Cypriot population than the 36,858 people who explicitly identified themselves as Greek or Turkish Cypriots in Table 3, especially when we remember that the first figure excludes all the British-born offspring of Cypriot parents who have by now established households of their own; likewise the figures in Table 4 provide the best available indication of the size of Britain's Vietnamese population (as well as of the size of its ethnic Vietnamese and ethnic Chinese components), as well as the East African Asians - the great majority of whom identified themselves as "Indian", even though in many cases their ancestors left the sub-continent 
several generations before; by contrast many more Mauritians have been classified as "Other Asian" (Table 3) despite their very similar ancestral origins.

Before we leave the subject there is one further feature of Table 4 which requires comment: the fact that nearly $10 \%$ of people belonging to households with Caribbean-born heads identified themselves in such a way (probably by writing British in the Black-other write-in box) that they were classified as Black-other by the O.P.C.S. coders. If one explores the issue further, one finds that no less than $23 \%$ of those whom the Census classifies as "Black-other" belong to households headed by someone Caribbean born (and a further $56 \%$ in households with a UK-born head), while an examination of the demographic profile of Britain's "Black-Caribbean" population reveals an otherwise wholly inexplicable deficiency of people at the youngest end of the age-spectrum (Ballard and Kalra, 1984). On the basis of this evidence we would suggest that many people of Afro-Caribbean descent regarded the ethnic question as asking primarily about birthplace, rather than ethnicity. If that was indeed the case many otherwise perplexing aspects of the published figures certainly fall rather neatly, if rather worryingly, into place: despite the best efforts of the question-framers, members of the otherwise socially unified British Afro-Caribbean community have been arbitrarily split between two different census categories, largely on the basis of age and birthplace. If that is indeed the case, it is as well to remember that a substantial proportion of those classified as "Black-other" will in fact be people of Afro-Caribbean decent, such that the best way of making an initial estimate of Britain's Afro-Caribbean population is to aggregate the two figures. However I would be the first to acknowledge the arbitrary quality of this method, since there can be no doubt that a substantial number of those classified as "Black-other" (although in my view only a minority) will not be of Afro-Caribbean descent.

But apart from these specific difficulties with the Afro-Caribbeans, all the indications are that the other four pre-coded options offered to the minorities in the Census document appears to have elicited a largely unambiguous response from its targets. This must be regarded as a major achievement. But by the same token it is equally clear that the two writein sections were largely a failure, at least in terms of generating meaningful data. The extent to which respondents took advantage of the opportunity to write in their own ethnic selfdefinitions was so limited that the results provide no useful information on smaller ethnic groups such as the Arabs, the Cypriots and the Vietnamese, nor indeed on the number of people of mixed parentage - always supposing that this latter target was ever likely be a viable part of the Census operation.

All this suggests a clear conclusion: if one's objective is unambiguously to identify minority groups, an essential prerequisite is the inclusion of appropriately marked boxes on the Census form itself.

\section{What was the Question for?}

Does it therefore follow that we should therefore aim to identify more ethnic groups in future Censuses? And to what lengths should we seek to go in identifying the various subcomponents of the minority presence? The answers one offers to such questions ultimately rests on what the object of the exercise is assumed to be all about. There is certainly scope for arguing that elaborate efforts to disentangle Black-African, Black-Caribbean and Black-British populations, or to separate out small groups such as the Cypriots, the Arabs, or the IndoCaribbeans amounts to nothing more than an academic pursuit of irrelevant exoticism, especially if one assumes that the sole purpose of including the new question in the Census was to gather data on the extent of racial disadvantage. If so, gathering data on internal differentiation amongst the visible minorities would indeed be a wholly irrelevant exercise, for there is no reason to suppose that intensity of exclusionism experienced by members of the 


\section{Roger Ballard}

visible minorities is affected in any way by their preferred modes of self-identification. Such an argument is wholly congruent with the perspective advanced in the only policy document which paid detailed attention to the purpose of the new question - the Select Committee Report referred to earlier. Its conclusions were quite explicit:

"the object of asking ethnic questions is, in conjunction with other indicators of general disadvantage, to assist Government and local authorities to identify and work against all aspects of racial disadvantage and racial discrimination" (HC 33 - 1, p. ix)

Yet despite the single-mindedness of the Select Committee's concern, it cannot be left to stand without scrutiny. Indeed now that we have the results before us it becomes essential to ask whether revealing the extent of racial disadvantage and discrimination could ever have been the sole - or even the principal - objective of the whole exercise.

\section{The significance of race versus ethnicity as an analytical category}

As we have seen, the debate about whether or not an ethnic question should be asked, and if so how it should be posed, was beset by considerable conceptual confusion. On the one hand the pre-set categories on the Census form were an ad hoc mixture of ethno-national and skin colour identifiers, while on the other hand even the most cursory exploration of the results brings us face to face with some difficult questions about just who and what it was that the Census was trying to count. In the same vein there is also an obvious contradiction between the adjective used to describe the question — ethnic — and the vocabulary which the Select Committee used to justify its inclusion, where all the emphasis is on racial disadvantage. Is there a real issue here, or is making a fuss about these apparently abstract conceptual distinctions mere academic nit-picking?

Manning Marable, a noted Afro-American scholar, has recently picked up this very point in a North American context. Having remarked that "because of the centrality of 'whiteness' within the dominant national identity, Americans generally make few distinctions between 'ethnicity' and 'race', and the two concepts are used interchangeably", he goes on to argue that from a Black American perspective the two concepts point to very different dimensions of their experience, the first being self-defined, and the second a consequence of exposure to white hegemony. But the distinction, he suggests, has remained largely unrecognised amongst the perpetrators. As he puts it, "Since so many Americans view the world through the prism of permanent racial categories, it is difficult to convey the idea that radically different ethnic groups may have a roughly identical 'racial identity' imposed upon them." (Marable 1994: 114). While there are necessarily all manner of differences between the British and the North American contexts, I would nevertheless argue that Marable's insights also hold good on this side of the Atlantic, above all because they show why questions about ethnic affiliation necessarily have very different implications from one about racial origin.

Let me explain. Despite the widespread British tendency to regard the terms ethnicity and race as synonymous, the essence of what ethnic affiliation is all about is not difficult to grasp: it is a matter of involvement in and commitment to a self-conscious community of some kind. However such affiliations are normally organised in a segmentary way: thus while southern English people may regard themselves as different from northerners, and amongst the latter Yorkshiremen may differentiate themselves strongly from Lancastrians, so amongst British Indians Gujaratis differentiate themselves from Punjabis, Hindus from Sikhs, upper castes from lower castes and so on and so forth. Moreover the strength of those feelings, as well as the level of ethnic affiliation which gives rise to active and overt social mobilisation is always context-dependent. Hence while we need always to bear in mind the complexities arising from 
the presence of such segmentary structures, it is about respondents' sense of belongingness to a community of some kind that ethnic questions — whatever their precise formulation enquire.

By contrast the concept of race has very different implications. Grounded in late nineteenth century assumptions about the role of skin colour as an indicator of biological (as opposed to social and cultural) distinctiveness, its primary emphasis on the difference - and indeed the alienness - of those identified as outsiders, rather than on commonalities amongst insiders. Hence as Manning emphasises, the experience of racial disjunctions varies a great deal depending on which side of the fence one stands. Given the routine use of skin colour as a social marker, all members of Britain's visible minorities share - and are far the most part very conscious of sharing - the common experience of being the objects of racial exclusionism; and it goes without saying that that experience is not of their own making. But while all those who share that experience are by definition members of a single social category, namely the targets of white exclusionism, this externally imposed and thoroughly unwelcome experience is rarely, if ever, the basis for the construction of communal loyalties of an ethnic kind. On the contrary the minorities' own agendas are invariably self-defined and therefore autonomous of majority values and expectations, whatever their dominators may assume.

However the perpetrators of racial exclusionism tend to see things very differently. Although racial disjunctions only arise because skin colour is regularly treated as a categorical social marker, most members of Britain's white majority are even less prepared to acknowledge that they themselves are primarily responsible for bringing those disjunctions about than are their counterparts on the far side of the Atlantic. Despite all the evidence to the contrary, the myth that Britain is a uniquely tolerant society still retains extremely widespread popular support. Hence - or so I would suggest — they not only tend to deny their own role in the creation of racial disjunctions with even greater vigour than do their American peers, but are also even more strongly committed to the assumption that " 'black' and 'white' are fixed, permanent and antagonistic social categories" (ibid.). If so there is good reason to expect that the assumption that ethnicity and race are necessarily synonymous concepts will be even more deeply entrenched in Britain than in the United States.

\section{Asking viable questions: race}

Separating these two concepts is far more than a matter of abstract theory, most particularly when questions have to be posed and the results interpreted. As I myself argued to the Select Committee (Minutes p. 157-160), there are good grounds for believing that questions about racial affiliation are almost unanswerable, at least if they are taken seriously on their own terms. Despite the resilience of the popular assumption that human beings can be divided into a number of distinct and clearly bounded racial groups on biological grounds alone, human geneticists have long since concluded that the taxonomic subdivisions into whose construction their nineteenth century predecessors put so much effort have little or no validity. While there is indeed a good deal of genetic variation within the species Homo Sapiens, these variations are clinal in character, and thus do not give rise to clear-cut boundaries between population groups; and since the clines for different genes also exhibit very little geographical congruence, ${ }^{6}$ the biological evidence makes it quite clear that "races" in the nineteenth century taxonomic sense are best regarded as little more than an artefact of mistaken and now discredited theories. Since any census question must of necessity ask respondents to identify

\footnotetext{
6 An excellent account of clinal patterns in the spatial distribution of gene frequencies, and the lack of congruence between the distribution patterns for different genes can be found in Bodmer and Cavalli-Sforza 1976: 559-603.
} 


\section{Roger Ballard}

themselves categorically, only one conclusion is possible: that to attempt to deploy questions grounded in a mistaken and now discarded ideology would be both silly and irresponsible.

Yet even though race in a biological sense is consequently a fiction, it would be quite wrong to conclude that the term is therefore empty of all meaning. Because skin colour (and certain other differences in physiognomy) is routinely used as a social marker, the racial disjunctions to which these practices give rise are real, as those who are subject to exclusion are only too well aware: hence, for example the now-widespread convention of setting the term race in inverted commas, as a means of indicating that the bodies of people so distinguished are best seen as constituting a social rather than a biological category. (Husband 199*) But even if we accept this essential qualification of the term, devising meaningful questions about membership of such racial categories is a far from straightforward task. This might seem odd, since no less than $94 \%$ of Britain's population appear to have ticked the "White" box with little or no hesitation, even though this involved giving an explicitly racial answer to what was billed as an ethnic question. But from the evidence we have reviewed so far there may also be another way of explaining what would otherwise be a logical contradiction. Since virtually everyone bar members of the visible minorities appears to have ticked the "White" box, their answers can also be read as an affirmation that they were not not-white.

Straightforward though this procedure may have seemed from a majority perspective for hardly anyone seems to have been aware that this is what they were doing, a minority perspective on the same issues necessarily leads to quite different conclusions. Although almost certainly far more acutely aware of the way in which skin colour is used to categorically assign social identities than are members of the indigenous majority, they are also acutely aware that it is not their own actions and conceptual vocabulary which leads to this outcome, but that of the majority. Hence from the point of view of the excluded, the only kind of a racial question with they would be likely to feel wholly at ease would have to be along the lines of "do you belong to that body of people who are likely to find themselves treated distinctively because of your non-white appearance?" My own experience suggest most members of Britain's visible support the asking of such a question with some enthusiasm, and would respond to it very positively.

However it is only too obvious that such a question would precipitate strong objections from the majority, not just because of its leading quality, but also because its inevitable partner would have to ask something along the lines of "or do you belong to that body of people who are likely to treat non-whites differentially because of their distinctive appearance?" The prospect of such a question being posed is self-evidently remote, since such an explicit acknowledgement of the majority's central role in the dialectics of racial categorisation would undoubtedly come far too close to the bone - even if the 51,810,555 people who ticked the "White" box without protest did indeed implicitly accept just such a perspective.

\section{Asking viable questions: ethnicity}

By contrast with all the pitfalls surrounding all questions about race, those about ethnic affiliation - which can be glossed as enquiring about the community to which respondents feel themselves to belong - appear to pose many fewer problems. The reason is simple: in this case questions seek to elicit information about membership of groups with which all respondents can be expected to positively identify themselves, rather than of social categories to which at least some people find themselves ascribed as a result of the baleful activities of others. Nevertheless there are a number of essential prerequisites which must be fulfilled if a 
specifically ethnic question is to proceed smoothly. First of all it is essential that each community of which the wider social order is made up has a commonly agreed upon name, which can then be used as an ethnic identifier. Secondly it depends on a comprehensive recognition that the wider social order does have such a plural character, for only then will it become universally acceptable for questions to be posed about membership of such communities. ${ }^{7}$ Given the segmentary character of ethnic affiliation which we noted earlier, a third requirement is that such questions should be pitched at an appropriate level of differentiation, neither so general as to lose all sense of specificity, nor so specific as to become both exoticising and intrusive. Fourthly and finally it requires a recognition that because most people participate at least to some degree in a range of different communities, it is quite inappropriate to use ethnic questions to try to establish what people are in an absolute sense: rather their object should simply be to identify which of those communities respondents feel themselves to be most closely affiliated.

Lets us explore the implications of each of these prerequisites in turn. As we have seen at least one very real and substantial community - Afro-Caribbean migrants and their Britishborn offspring - have not coined a comprehensively agreed upon collective identifier, and that this did and still does cause major problems. ${ }^{8}$ However there are strong indications that the difficulties experienced by British-Afro-Caribbeans are a unique consequence of their stillunresolved historical experience, and that no other minority groups, whether visible or invisible, find themselves in the same position. All the indications are that Yemenis, Somalis, Filipinos, Greek and Turkish Cypriots, Poles, and Jews, let alone the Scots, the Welsh and the Irish will very willingly identify themselves as such, always provided that such an identification is not regarded as evidence that they are in some way not-British.

Paradoxically enough the only other section of Britain's population which does indeed appear to have severe difficulties with the prospect of representing itself in ethnic terms is the English majority. Yet why should this be so? That the English are in any way doubtful about their own cultural distinctiveness can of course be discounted immediately: if that were so, appeals for a "cricket test" would make no sense whatsoever. Rather their reluctance to accept an ethnic self-identification appears to have much deeper roots, above all because doing so would not only require them to acknowledge that like everyone else the English are hyphenated Brits, and that every other ethnic component of the United Kingdom's plural society is no less British than theirs. Hence I would argue that it is with the second of my prerequisites that Britain's English majority runs into difficulty, largely because its members have hitherto been able to take their own position of hegemony for granted. Challenging that has proved to be just to much to bear - hence, amongst other things, their otherwise perplexing willingness to use skin colour as their principle vehicle for self-identification.

\footnotetext{
It is essential to stress the voluntary character of ethnic affiliation, above all to differentiate it from Apartheid-like systems in which "tribal" differentiation was ascribed by the state.

${ }^{8}$ A parallel debate about the collective noun by which they would prefer to be identified has also taken place amongst Black Americans. In their first, somewhat limited attempt to distance themselves from the derogatory label "Nigger", they renamed themselves "Coloured people", before this was replaced by the more vigorously assertive identifier "Black" during the nineteen sixties. Since then rising awareness of their ethnic distinctiveness has led to an ever-wider adoption of the term "Afro-American", recently revised to "AfricanAmerican". There is good reason to believe that Britain's African-Caribbean population may well be following a rather similar trajectory, given their parallel historical experience of slavery. But since the formative ground for many of their cultural traditions lay in slave colonies which were not a part of the British mainland, and which are consequently regarded as external to their current domicile (unlike the Southern States of the USA), and since Britain's population also contains a considerable number of direct migrants from Africa (again unlike the USA), finding a permutation of the terms African, Caribbean, British and Black with which everyone can feel at ease has so far proved elusive.
} 


\section{Roger Ballard}

The majority preference for a racial rather than an ethnic approach to self-definition - at least in Census contexts - has had many further consequences. Since it further reinforced the erroneous assumption that ethnicity is best understood as synonym for visibility, there is good reason to suppose that this usage inhibited Britain's less visible minorities from emphasising their ethnic presence. Hence, for example, the high frequency with which Cypriots ticked the "White" box is almost certainly better read as an indication of their wish to represent themselves as not non-European than any lack of awareness of their own distinctive sense of ethnic belongingness. A further consequence of the essentialising tendencies precipitated by the majority preference for a vocabulary of race has also been to assign a problematic status to those of mixed ancestry. Hence, for example, this was a category of persons who were specifically asked to identify themselves in a rider to the ethnic question, and which O.P.C.S. appears to have hoped to classify in a meaningful way, given the way in which they set about categorising write-in answers. That Britain's population now contains a substantial number of people of mixed ancestry is clearly beyond doubt, for despite the strong preference for endogamy displayed by most minority groups, by no means all marriages conform to that pattern. Bearing this in mind, the number of persons of mixed ancestry shown in the bottom four rows of Table 2 is manifestly a gross underestimate. Yet does this matter? Is measuring the extent of such mixture an issue which we can legitimately expect the Census to explore? My own view is that it is not, and for reasons that are most instructive.

In the first place an exploration of the extent of biological admixture must by definition be unrealistic: if races in the sense of sub-species are largely fictional constructs, so, a fortiori, is any attempt to record and classify mixtures between them. And although race as a sociological phenomenon is real enough so long as a non-white skin colour is used as a mark of inferior social status, "mixture" is manifestly quite irrelevant here: everyone physically distinguishable is liable to find themselves marked out in this way, regardless of the details of their ancestry. What, though, about the prospect of having mixed ethnic affiliation? Although children with parents of differing backgrounds are more likely than most to participate in the activities of several different communities, such an experience is quite obviously not unique to people of mixed parentage. Nor is such a way of life in any way pathogenic: in a plural society transactions constantly occur across ethnic boundaries, and those who do so soon become skilled cultural navigators, able to act and react appropriately in a range of cultural contexts. ${ }^{9}$ However such navigational skills are much better viewed as an asset than as a necessary source of confusion about one's personal or ethnic identity, always provided that ethnic affiliation is perceived as a relative rather than an absolute issue. Hence ethnic questions should always be understood to invite a single answer, no matter how polysemic the respondent's experiences or hereditary antecedents may be. Unlike race, ethnicity is always a matter of self-ascription.

Taking all these arguments into account, we can now begin to make much better sense of how the ethnic group question came to work as well as it did. Those who ticked the "White" box are best understood as having approached the question from a racial perspective, and their answers are best understood as confirming that they do not belong to any of the visible minorities specified in the boxes below. By contrast those who ticked any of the other boxes are best understood as having understood the question from an ethnic rather than a racial perspective, with the result that the most reliable ethnic data to have emerged from the Census is that about six minority groups specifically named in the question; and while estimates of the size of some other minority groups (both visible and invisible) can be arrived at by associating

\footnotetext{
9 It is in the nature of the situation that members of minority groups tend to have much more highly developed navigational skills than do members of the majority. The former regularly participate in latter's world, while the reverse much more rarely occurs. Moreover one of the central privileges of hegemony is the ability to insist that others conform to one's own linguistic and cultural agenda.
} 
answers to the ethnic question with data from elsewhere in the Census, this provides us with no meaningful information (assuming it could ever exist) on the extent of either racial or ethnic admixture.

\section{Interpreting the Results}

Important though it may be in showing us how respondents set about answering the question, the distinction between racial as opposed to ethnic perspectives is no less significant when it comes to interpreting the results. The reasons are quite straightforward: despite the Select Committee's expectation that principal benefit of including the question would be to establish the extent of racial disadvantage and discrimination, the picture that emerges from the results has proved to be a great deal more complex. As my own preliminary exploration of the data (Ballard and kalra 1994) very clearly indicated, and as almost every contribution to these volumes graphically confirms, whichever dimension of the results one chooses to explore be it demography, household formation and membership, employment, education or housing - the scale of inter-minority differences is at least as great as (and very often greater than) that between the majority and the minorities taken as a whole. Hence anyone who expects to be able to read off the extent of racial disadvantage in contemporary Britain from a simple inspection of the the raw will be gravely disappointed.

How is this to be explained? One possibility is of course that racial discrimination is far less extensive than most sociological commentators have assumed, and thus that the whole concept of racial disadvantage is therefore itself largely fictional; moreover such a conclusion is all the more plausible given the determinist perspective which has for so long been the basis of the received opinion in sociological theory. But if one is to challenge the apparently commonsense view that the Census data seems to indicate that racial exclusionism has only the most marginal impact on the lives of the new minorities, on what basis should we seek to proceed? In the first place it can most certainly be argued that it is quite inappropriate to regard racial disadvantage as a freestanding variable, that the proper course is to conduct a much more sophisticated regression analysis in order to explore the interaction between racial disadvantage and a range of other vectors social inequality such as gender, social class, age, spatial location and so forth (See Chapter ?? in this Volume). But however illuminating the results of these statistical analysis may be, there is still good reason to doubt whether such approaches will come anywhere near a comprehensive explanation of inter-ethnic differences. And for very good reason. While the condition of being "not-white" is indeed best understood as a handicap - if only because those who identified themselves as "White" thereby allocated themselves to a categorical position of privilege - ethnicity is a wholly different kind of phenomenon, above all because it points to the capacity of people who belong to differing communities to define their own agendas, whatever others may think of them, and however they may treat them.

It is on these grounds that I would argue that any analysis which fails to take the potential of such ethnic capabilities into account, and which is therefore unable to perceive that these entrench be strengths rather than weaknesses, and assets rather than unfortunate handicaps will find it well-nigh impossible to account for the inter-ethnic variations which the Census results so graphically highlight; and if one cannot, one is left with very few defences against the proposition that racial exclusionism is only of marginal significance in contemporary Britain. What, them, is the alternative? As will by now be obvious, my own view is not so much that racial exclusionism is non-existent, but that our analytical perspectives stand in need of radical revision. In particular we need to recognise the gross inadequacy of the monochromatic perspective which still informs so much current thinking in sociology and social policy; if, by contrast, we add to this the much more dynamic perspective which I have advocated here, and which takes far more seriously the prospect that minorities can and do use 


\section{Roger Ballard}

the resources of their ethnicity to resist and to circumvent the worst impact of racial exclusionism, we not only generate an understanding of the contemporary social order which gives much greater scope for considerations of agency, but in so doing project a vision of its texture which is far more congruent with real-world outcomes than that generated by conventional sociological theory.

Yet the task here seems unlikely to be straightforward, given that the shift in perspective which is a necessary consequence of the inclusion of an additional dimension in one's analytical kitbag is one with which some people may well find unwelcome. Just as flatfish used only to hugging the seabed might be so alarmed by suggestions that the ocean had depth as well as width and breadth that they rejected theories which rested on the premise that they actually lived in a three-dimensional world out of hand, so there is equally good reason to expect that those who have hitherto lived in a deterministic world where race and ethnicity could be regarded as mere synonyms will be equally resistant to acknowledging the need to prize the two apart. Quite apart from the conceptual upheaval that such a shift entails, it should also be remembered that the privileged position accorded to eurocentric perspectives - the very bedrock for the maintenance of majority ideological hegemony — is more easily rendered invisible if the very possibility that an autonomous ethnic dimension might exist is comprehensively denied.

Yet for those who have eyes to see, the Census provides the clearest possible evidence of both the existence of this dimension and of its significance. Even though everyone bar the visible minorities may have passed up the opportunity to highlight their own internal diversities by identifying themselves as White, members of those minorities did just the opposite: given the opportunity to speak for themselves, they exhibited a clear preference for identifying themselves in ethnic terms, and thereby sidestepped the majority's monotonously monochromatic agenda. Given that they have thereby shown that they are quite capable of setting their own agendas of self-identification, it should therefore come as no surprise that they also exhibit just the same capacity with respect to all other dimensions of their lives, for even though racial exclusionism may be a constant constraint, it by no means determines their behaviour. If so it follows that any attempts to analyze their social, educational and economic experiences which fails to make simultaneous reference both to the extent to which their behaviour might be constrained by encounters with racial exclusionism and the extent to which it may also be inspired by their own distinctive ethnic preferences must be regarded as unsound.

If Census outcomes are therefore best understood as the result of the simultaneous operation of both constraint and choice, distinguishing between the relative impact becomes an urgent analytical task; and although this is no place to conduct such an analysis we can at least spell out the basic framework within which it might be conducted. In racial terms Britain's visible minorities are most appropriately regarded as forming a social category of black people; as such they do indeed occupy a position of disadvantage whose extent is directly proportional to the strength of the exclusionism to which they find themselves exposed. But even though everyone assigned to this social category will share, by definition, a common social experience, and although they themselves will tend to be far more conscious of their condition than are their excluders, it is both idle and deeply patronising to suggest that their lives and life-chances are wholly determined by these constraints, no matter how serious they may be. Just as the minorities have refused to follow their excluders' agendas in terms of selfidentification, so they have responded to racial exclusionism by devising with their own varied and above all self-determined strategies of resistance.

This is not to suggest that resistance is in any way a uniquely ethnic phenomenon: on the contrary I would suggest that members of all excluded groups - be they women, children, elderly or deaf, to mention a few examples - have likewise developed alternative moral, 
symbolic and linguistic agendas of their own. What does distinguish migrants from other excluded minorities, however, is their ability to access the immense storehouse of values, symbols and understandings which they brought with them from overseas, and whose resources they have been able to draw as a source of inspiration for organising their lives on an alternative basis the better to survive in their new surroundings. Once the existence of such potentialities is recognised, the fact that the visible minorities' aggregate position in the housing and employment markets, and that their mean educational achievements is both far less adverse and for more varied than more deterministic theories would have predicted becomes very much less problematic. Once ethnic capabilities are regarded as an asset rather a handicap, none of this need cause any surprise: it is precisely the minorities' ability to access an alternative set of culturally, linguistically and religiously grounded resiliences which has given them such a striking capacity to resist — or at the very least to circumvent — the dead hand of racial exclusionism.

As soon as one adopts this kind of dialectic perspective, the complexities of observed outcomes fall swiftly into place: only if the minorities were indeed the helpless pawns that determinist theory all too easily suggests would it have been possible to use Census outcomes to read off the extent of racial disadvantage in a straightforward way. Yet although data associated with the new ethnic variable may therefore tell us surprisingly little about the extent of racial exclusionism per se, it is certainly not the case that it has nothing to contribute on that front. On the contrary it constitutes an invaluable source of reliable denominators against which to compare ethnic records of recruitment, selection and promotion within specific companies, hospitals, universities and so forth, thus enabling them to check out the effectiveness of equal opportunities policies. But besides enhancing our capacity to conduct such relatively conventional exercises, by far the greatest value of the ethnic data as a whole is that it allows us to make a far more sophisticated assessment of the increasingly varied positions which the new minorities now occupy in the British social order, and to begin to explore the adaptive strategies by means of which they have achieved these positions.

In the course of such an exercise it would, of course, be quite unnecessary to make any prior assumptions about the relative importance of external constraints as opposed to internal preferences, for it is only to be expected that this will vary situationally. In some contexts exclusionism may be so severe that the countervailing impact of internal ethnic preferences will have only the most marginal influence on outcomes; but there will also be others where the reverse is the case. If so, careful analysis of ethnic data from Census data offers us an opportunity to subject my largely theoretical arguments to thoroughgoing empirical scrutiny. But if that course is indeed successfully to be pursued, analysts will need to be aware of all the many pitfalls that lie along the way, not least because the uncritical use of anglocentric perspectives to assess minority behaviour will necessarily bring with it the prospect that difference will be misinterpreted, and worse still, pathologised. As we have already seen, there is no way in which the significance of the ethnic labels deployed in the census can be properly understood without careful reference to the way in which differing groups of respondents interpreted them. For just the same reasons any analysis of inter-ethnic variation which is undertaken in the absence of a reasonably intimate ethnographic knowledge of the minority lifestyles, and hence of the (changing) values, expectations and goals around which members of each component section of our plural society has constructed itself must necessarily be regarded as inadequate.

To sum up, what a serious exploration of this dimension of the Census serves to highlight is that neither the social, moral and economic goals of Britain's many ethnic communities, nor the styles, conventions and strategies which those involved use to reach those goals can possibly be taken for granted, and that they must therefore be the subject of careful empirical investigation. Any analysis which fails to address these issues can hardly avoid treating the 


\section{Roger Ballard}

values and expectations of the hegemonic majority as the very yardstick of normality whether or not the analyst is conscious of so doing. Moreover any such procedure will not only generate profoundly ethnocentric conclusions, but will also constitute yet another brick in the wall of ethnic hegemony.

\section{Issues for the future}

One final set of issues that it is also worth confronting relates to the adequacy of the question as posed, and whether, therefore, it might be improved upon in future Censuses, most particularly with respect to the way in which respondents are invited to categorise themselves. While this is in part a technical issue, it is also worth remembering that it would be idle to expect such categories to run ahead of social reality. Hence if there was no agreed upon term with which all British-African-Caribbean people might wish to identify in 1991, there was no way in which the Census could be expected to impose one; however it may well be that such an agreed-upon identifier will have emerged by 2001 . However as much of my discussion here has sought to show, by far the largest problems of ethnic labelling arose with respect to the majority. Given that the categorical labels which generated the most unambiguous information about clearly defined population groups were those which were most ethnically specific, it follows that if the racial options offered in 1991 were eliminated, and were instead replaced them with a considerably wider range of ethnic identifiers, the overall quality of the results would be greatly improved.

Much would follow from the adoption of such a strategy. First of all the catch-all category "White" could be unpacked, at the very least by providing a single box marked "English, Welsh, Scottish or Irish", or better still by providing a separate box for each group. Amongst other things this would have the further benefit of making space for the non-visible minorities to identify themselves if they so chose, especially since there are now strong indications that the Board of Deputies of British Jews has begun to reconsider its hitherto adamant opposition to any suggestion that members of their community might be expected publicly to identify themselves as such. ${ }^{10}$ Now that memories of the holocaust loom slightly less large than they one did, so the American experience, where Jews have joined many other minorities in feeling that they should stand up and be counted, is becoming steadily more influential. So although the Board of Deputies has yet to make any formal declaration on the subject, if British Jews did see it as being in their interest to assert themselves more overtly as an ethnic minority the knock-on effect would undoubtedly be considerable. Amongst other things it could well be that Britain's Roman Catholic population (the vast majority of whom are in fact of Irish descent ${ }^{11}$ ) would wish to do the same.

A second useful initiative would be facilitate the explicit identification of a whole series of smaller visible and semi-visible minorities, such as Greek and Turkish Cypriots, Yemenis, Somalis, Iranians, Vietnamese and so forth. There would appear to be no practical problems in doing so. Draft questions inviting members of several of these groups to identify themselves were included in the trials conducted before the 1991 Census, but for no very obvious reason were omitted from the final version.

10 I have yet to show a copy of this draft to Marlene Schmool, Research Officer for the Board of Deputies. An up to date footnote on the current position will be included in the final draft.

11 Figures for Persons born in Ireland which O.P.C.S. included in several of the Ethnic Group Tables may be interesting in their own right, but they are an extremely poor guide to the scale of Britain ethnic Irish population, given that mass migration across the Irish sea began more than a century and a half ago. The Irish constitute by far the largest of Britain's ethnic minorities; though precise numbers are unknown, they are undoubtedly a great deal more numerous than the entire population of all the visible minorities put together. 
A thirdly major benefit of a such an approach is that it would facilitate the identification of major sub-divisions within currently recognised ethnic categories. For example one draft tested out in 1985 invited those who had identified themselves as "Indian", "Pakistani" or "Bangladeshi" to further specify whether they were "Muslim", "Hindu" or "Sikh"; yet despite the high level of response amongst South Asians, its inclusion in was rejected on the grounds that "the addition of a religious question had no discernible effect on the quality of the answers given by Southern Asians to the main ethnicity question." (Sillitoe and White 1992, p.150)

This curious conclusion brings us right back to where we began: to the very purpose of asking ethnic questions. Sillitoe and White's argument only makes sense if ethnicity is perceived as nothing more than a surrogate for colour: if so, it follows that the quality of the answers would be adjudged solely by the extent to which they facilitated the categorization of the population as either "White", "Black" or "Brown". However as soon as our agenda shifts in a more pluralistic direction, and therefore seeks to explore the poly-ethnic character of British society, we enter very different territory. Here the central objective of an ethnic question is at least in principle to identify all the various components of British society in terms that make sense to those who belong to them. Hence if Catholics, Jews, Muslims, Sikhs and Hindus so identify themselves, not so much in terms of religious belief, but as members of communities with their own distinctive interests and concerns, ethnic questions should surely seek to acknowledge those commitments.

What is at stake here is the issue of pluralism. Once we recognise that Britain is (and long has been) a wide range of communities and sub-communities, it follows that besides articulating their own distinctive set of interests and concerns, the members of each such community will in all probability be be following an equally specific social, economic and spatial trajectory. Besides bringing these diversities into much clearer focus than ever before, the inclusion of an ethnic question in the Census also gives us an opportunity to track their consequences in a positive way. To be sure those who have hitherto viewed race, ethnicity and deprivation as virtually synonymous may well find this shift in perspective most unsettling, since it cuts so much established ground from beneath their feet; but whether or not they choose to acknowledge it, such unease is largely the outcome of a reluctance to accept that others' agendas will necessarily — and quite legitimately — differ from one's own. What is at stake here is the perspective we take on the character of the society in which we live. Just as flatfish will find themselves forever trapped by the conceptual limitations of their twodimensional world until become confident enough to abandon the comfortable familiarity of the ocean floor, so those who fail to develop even the most basic skills of cultural navigation will tend to remain equally oblivious to the ethnic potentialities surrounding them.

Hegemonic social practice is invariably grounded in the self-confident maintainance of such a myopic perspective, regardless of all evidence to the contrary. Much more by accident than design, the ethnic question in the census has now provided us with plentiful evidence of the strength of ethnic potentialities, and of the radical changes which are thereby being wrought in Britain's social order: we ignore them at our peril. 


\section{References}

Alderman, Geoffery Modern British Oxford: Clarendon Press, 1992.

Ballard, Roger "On the Question of Ethnicity", Minutes of Evidence to the Home Affairs Committee HC 33-1, (1982) Vol. 2, pp.157-160.

Ballard, Roger "Race and the Census: what an 'Ethnic Question' would show" in New Society, 12th May 1983. p. 212 - 214

Ballard, Roger "New Clothes for the Emperor? The Conceptual Nakedness of the British Race Relations Industry", New Community (1992) 18 pp. 481 - 492.

Ballard, Roger Desh Pardesh: The South Asian Presnce in Britain London: Hurst and Co., 1994

Ballard, Roger and Kalra, Virinder The Ethnic Dimensions of the 1991 Census: a Preliminary Report University of Manchester: Census Dissemination Unit, 1994

Bodmer, Walter, and Cavalli-Sforza, Luigi Genetics, Evolution and Man San Fransisco: W.H. Freeman, 1976

Brook, Stephen The Club: Jews of modern Britain. London: Constable, 1989.

Eriksen, Thomas Hylland Ethnicity and nationalism: anthropological perspectives. London : Pluto Press, 1993.

Fielding, Steven Class and Ethnicity: Irish Catholics in England Manchester: Manchester University Press, 1992

Holmes, Colin A Tolerant Country? London: Faber and Faber, 1991

Home Affairs Committee of the House of Commons Ethnic and Racial Questions in the Census HC 33-1 1983

Marable, Manning "Beyond racial identity politics: towards a liberation theory for multicultural democracy" Race and Class (1994) 35, pp. 113-130.

Mayhew, London Labour and the London Poor, 4 Vols. London, 1861-2, reprinted New York, 1968.

Sillitoe K. and White, P.H., "Ethnic Group and the British Census: the Search for a Question" J.R.. Statist. Soc. A (1992) 155, Part 1, pp. 141-163.

Sillitoe, K., "Questions on race/ethnicity and related topics for the Census" Population Trends (1987) 49 pp. 5-11.

Watson, James Between Two Cultures: Migrants and Minorities in Britain London: Blackwell, 1977 